\title{
Air-sea humidity effects on the generation of tropical Atlantic SST anomalies during the ENSO events
}

\author{
Yoshimitsu Chikamoto $^{1,2}$ and Youichi Tanimoto ${ }^{3}$ \\ Received 21 June 2006; revised 17 August 2006; accepted 31 August 2006; published 4 October 2006.
}

[1] After the mature stage of the ENSO events in the boreal winter, SST and latent heat flux anomalies over the tropical Atlantic during the following spring show large amplitude north of the equator but small one south of the equator. The linear decomposition analyses of the latent heat flux anomalies indicate that the contribution from wind speed anomaly shows an equatorial antisymmetric structure with same magnitude but opposite polarity between north and south of the equator, while the contribution from anomalous air-sea humidity difference counters to that from wind speed anomaly south of the equator. These results suggest an important role of anomalous air-sea humidity difference on forming latent heat flux anomaly and significantly modifies the conventional view of wind speed as the dominant effect in ENSO-induced tropical Atlantic SST changes. Citation: Chikamoto, Y., and Y. Tanimoto (2006), Air-sea humidity effects on the generation of tropical Atlantic SST anomalies during the ENSO events, Geophys. Res. Lett., 33, L19702, doi:10.1029/2006GL027238.

\section{Introduction}

[2] Sea surface temperature anomalies (SSTAs) in the eastern tropical Pacific during the El Niño and the Southern Oscillation (ENSO) events affect thermal structure in most of the tropical atmosphere [e.g., Wallace et al., 1998 and references therein]. Specifically, in the tropical Atlantic, positive (negative) SSTAs are observed in the northern tropical Atlantic during the March-May (MAM) period after the mature stage of the ENSO warm (cold) events, while no significant SSTAs are observed in the southern tropical Atlantic near the equator [Covey and Hastenrath, 1978; Curtis and Hastenrath, 1995; Giannini et al., 2000]. In the southern tropical Atlantic, total SST variance during the boreal spring-summer season explained by ENSO is less than 10\% [Enfield and Mayer, 1997; Liu et al., 2004] although a SST response to ENSO has appeared during October-December period [Reason et al., 2000; Colberg et $a l .$, 2004]. If we focus only on the SST variability after the mature stage, we would expect that the atmosphere-ocean variability over the southern tropical Atlantic is not related to the ENSO variability.

[3] For the SST variability in the northern tropical Atlantic, many previous studies indicated an important

\footnotetext{
${ }^{1}$ Graduate School of Environmental Earth Science, Hokkaido University, Japan.

${ }^{2}$ Now at Disaster Prevention Research Institute, Kyoto University, Japan.

${ }^{3}$ Faculty of Environmental Earth Science, Hokkaido University, Japan.
}

Copyright 2006 by the American Geophysical Union. 0094-8276/06/2006GL027238\$05.00 contribution from surface wind speed changes during the ENSO events [Curtis and Hastenrath, 1995; Enfield and Mayer, 1997; Klein et al., 1999; Giannini et al., 2000; Hastenrath, 2000; Lau and Nath, 2001; Alexander and Scott, 2002]. Over the northern tropical Atlantic, the positive (negative) SSTAs are collocated with anomalous surface southwesterlies (northeasterlies) after the mature stage of the ENSO warm (cold) events. These surface wind anomalies induce changes in evaporation from the ocean surface, contributing to the formation of SSTAs in this region. An observational analysis by Curtis and Hastenrath [1995] showed that, after the surface wind anomalies appear over the northern tropical Atlantic in January-February period during the ENSO warm (cold) events, anomalous southeasterlies (northwesterlies) over the southern tropical Atlantic emerge in the following MAM period. These crossequatorial southerlies are also presented by Huang et al. [2002], who use an atmosphere-ocean general circulation model coupled over the Atlantic region. Over the southern tropical Atlantic, however, the surface wind speed changes after the mature stage of the ENSO events do not accompany significant SSTAs in these observational and modeling studies.

[4] Recent studies pointed out an important contribution from anomalous air-sea humidity and temperature differences in forming the tropical Atlantic SSTAs after the mature stage of the ENSO events [Saravanan and Chang, 2000; Chiang and Sobel, 2002; Chiang and Lintner, 2005; Chikamoto and Tanimoto, 2005]. Chiang and Sobel [2002] suggested that tropospheric temperature variability over the tropics associated with the ENSO events can change surface air humidity and surface temperature over the tropical Atlantic under the strict quasi-equilibrium (SQE) concept [Emanuel et al., 1994; Brown and Bretherton, 1997] which states the conservation of the convective available potential energy (CAPE). These surface humidity and temperature variations may produce changes in air-sea humidity and temperature differences, inducing local change in SST through surface latent and sensible heat flux variations. Chikamoto and Tanimoto [2005] indicated that SSTAs in the Caribbean Sea are mainly formed by anomalous air-sea humidity difference that correlated with temperature anomalies in the free atmosphere over the tropical Atlantic after the mature stage of the ENSO events.

[5] In this study, we will examine why no significant SSTAs are observed in the southern tropical Atlantic despite the fact that surface wind anomalies are found in the same region after the mature stage of the ENSO events. Over the tropical Atlantic, previous observational studies indicated that latent heat flux anomaly is the major contributor to surface net heat flux anomaly, while radiative heat fluxes associated with cloud changes and ocean dynamics are the 
COADS

(a) SST (MAM) \& surface wind (FMA)

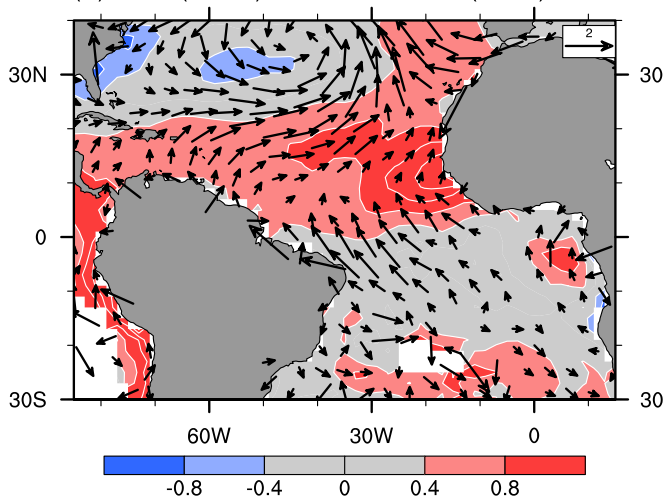

(b) latent heat flux (FMA)

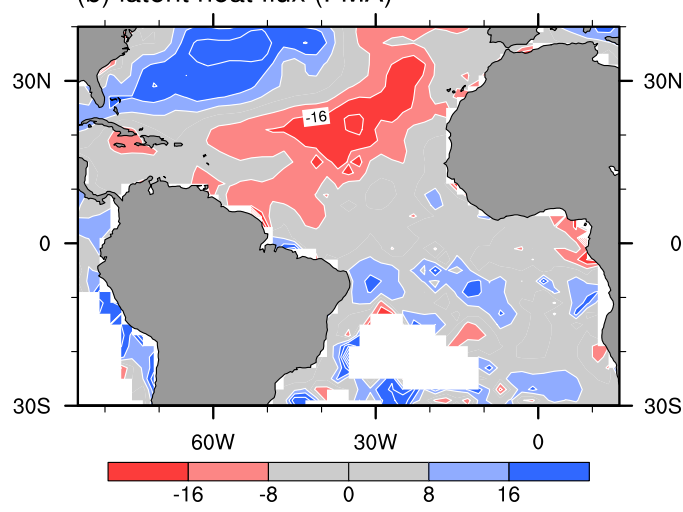

NCEP2 \& OI SST

(c) SST (MAM) \& surface wind (FMA)

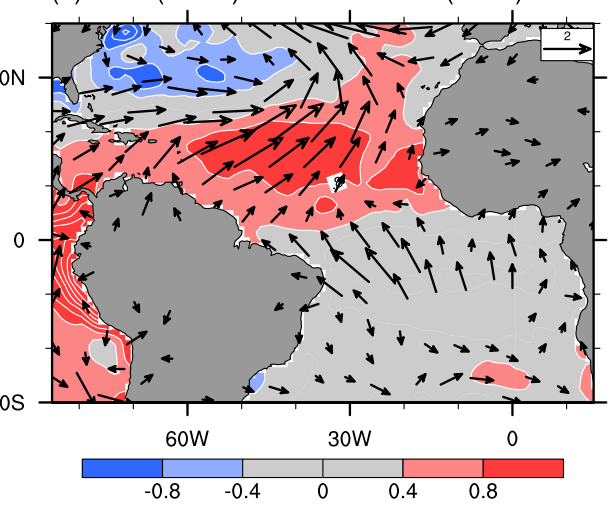

(d) latent heat flux (FMA)

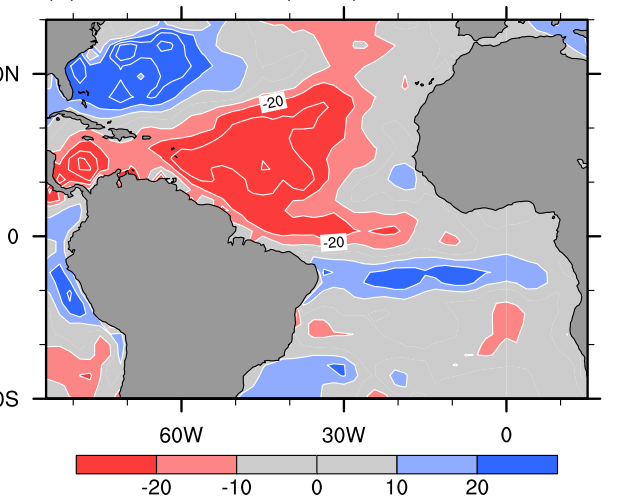

Figure 1. Composite difference maps of (a, c) SSTAs (contour, ${ }^{\circ} \mathrm{C}$ ) during the MAM period and surface wind anomalies (vector, $\mathrm{m} \mathrm{s}^{-1}$ ) during the FMA period and $\left(\mathrm{b}, \mathrm{d}\right.$ ) latent heat flux anomalies (contour, $\mathrm{W} \mathrm{m}^{-2}$ ) during the FMA period between the ENSO warm and cold events. Left (right) plots are based on COADS (NCEP2 and OISST). Zero contours are omitted. Warm (cold) colors in bottom plots indicate heat gain (loss) from the ocean.

minor contributor near the equator after the mature stage of the ENSO events [Curtis and Hastenrath, 1995; Klein et al., 1999; Alexander and Scott, 2002]. Therefore, we will focus on the relative importance among anomalous air-sea humidity difference and surface wind anomaly in forming SSTAs over the southern tropical Atlantic.

\section{Data}

[6] To capture the ENSO-related variability over the tropical Atlantic, we employ the $2^{\circ} \times 2^{\circ}$ monthly surface fluxes based on individual marine meteorological reports archived in Comprehensive Ocean-Atmosphere Data Set (COADS) [Woodruff et al., 1987] during a 1950-1995 period (for more details see Tanimoto et al. [2003]). Since this non-assimilated data may contain sampling errors in the region of few marine reports, we also use monthly surface fluxes during a 1982-2002 period based on the National Centers for Environmental Prediction-Department of Energy Atmospheric Model Intercomparison Project-II Reanalysis (NCEP2) [Kanamitsu et al., 2002], in which the atmospheric boundary layer humidity tends to depend on model parameterizations of cumulus convection and boundary layer physics, and the National Oceanic and Atmospheric Administration optimum interpolation SST version 2 (OISST) [Reynolds et al., 2002]. Vertical profiles of temperature and humidity at Ascension Island $\left(8^{\circ} \mathrm{S}\right.$, $14^{\circ} \mathrm{W}$ ) are taken from the radiosonde observations in Comprehensive Aerological Reference Data Set (CARDS) [Eskridge et al., 1995] from February 1971 to July 2001.

[7] To represent the magnitude of the ENSO warm and cold events, we extract eight warm (cold) years of 1957/58, $65 / 66,72 / 73,82 / 83,87 / 88,91 / 92,94 / 95$, and 97/98 (1955/ $56,67 / 68,70 / 71,73 / 74,75 / 76,84 / 85,88 / 89$, and 99/00) from SSTAs in the Niño3 region as described by Chikamoto and Tanimoto [2005]. Hence, we take the warm (cold) events of 7 (7) years in the longer record of COADS and of 5 (3) years in the shorter records of NCEP2 and OISST. We analyze composite difference maps between the ENSO warm and cold events (hereafter, simply referred to as composite). The vertical profiles derived from CARDS consist of 354 (304) samples during the ENSO warm (cold) events.

\section{Results}

[8] Figure 1 shows composite difference maps of SSTAs in MAM period, surface wind and latent heat flux anomalies in February-March-April (FMA) period. In both datasets of COADS and NCEP2, anomalous surface southwesterlies 
COADS

(a) W' component

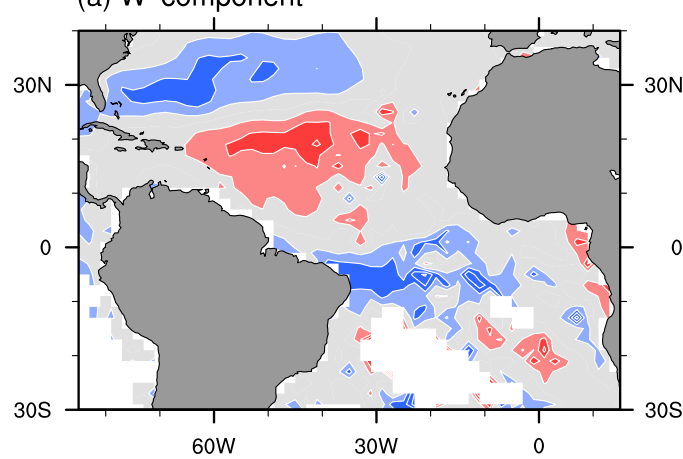

(b) $\Delta q^{\prime}$ components

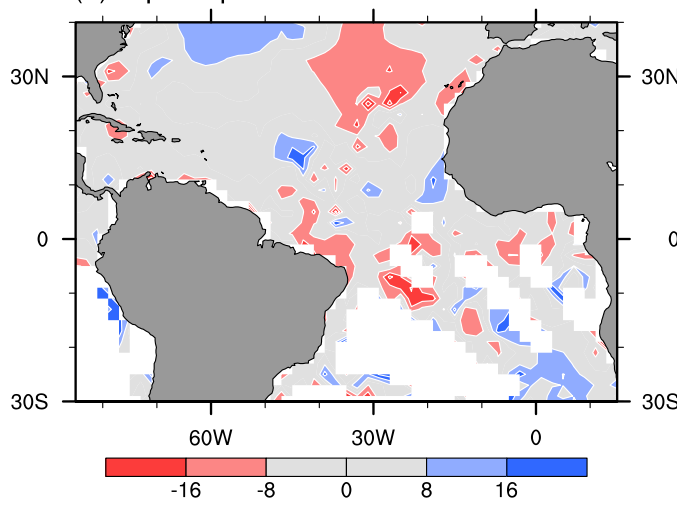

NCEP2 \& OI SST

(c) W' component

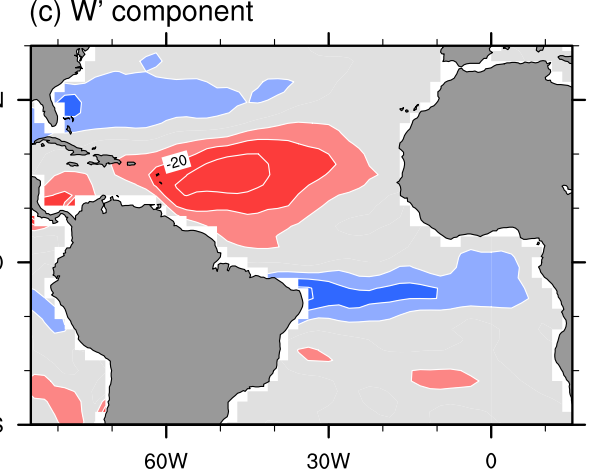

(d) $\Delta q^{\prime}$ components

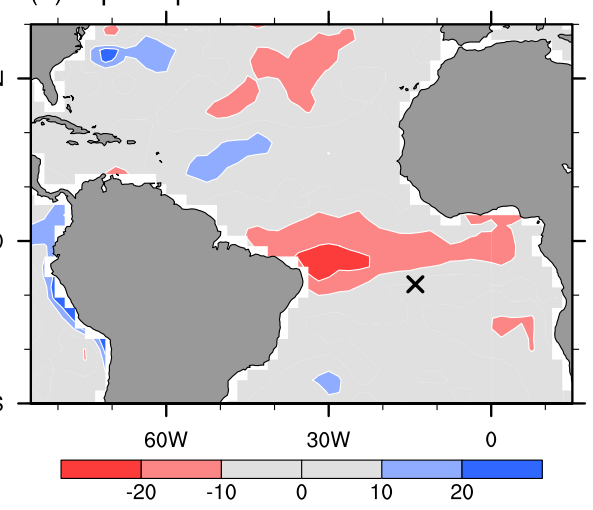

Figure 2. Same as Figures $1 \mathrm{~b}$ and $1 \mathrm{~d}$ but for contributions from $(\mathrm{a}, \mathrm{c})$ wind speed anomalies $\left(W^{\prime}\right)$ and $(\mathrm{b}, \mathrm{d})$ air-sea difference in specific humidity $\left(\Delta q^{\prime}\right)$ to latent heat flux anomalies. Cross in Figure 1d indicates the station at Ascension Island.

of $1 \mathrm{~m} \mathrm{~s}^{-1}$ extending from the Caribbean Sea to the west coast of Africa are observed (Figures 1a and 1c), showing reduced climatological easterly trade winds. Under these anomalous surface winds, significant positive SSTAs greater than $0.4^{\circ} \mathrm{C}$ and negative latent heat flux anomalies less than $-10 \mathrm{~W} \mathrm{~m}^{-2}$ are also observed (Figures 1a-1d). Surface heat flux anomalies of $-10 \mathrm{~W} \mathrm{~m}^{-2}$ are nearly equivalent to an increase in SST of $0.4^{\circ} \mathrm{C}$ for 3-month in mixed layer of $50-\mathrm{m}$ depth. In the region north of $20^{\circ} \mathrm{N}$, anomalous surface westerlies show enhancing climatological westerly winds, contributing negative SSTAs off the east coast of North America.

[9] Over the southern tropical Atlantic, anomalous surface southeasterlies over $0-10^{\circ} \mathrm{S}$ band are as much as $1 \mathrm{~m} \mathrm{~s}^{-1}$ in magnitude, showing enhanced climatological southeasterly trade winds. Nevertheless, magnitude of latent heat flux anomalies over the southern tropical Atlantic in the same band are less than half those of northern tropical Atlantic. In addition, no significant SSTAs are observed in the southern tropical Atlantic from equator to $20^{\circ} \mathrm{S}$. This result suggests that some other factors may reduce latent heat flux anomalies. In the region south of $20^{\circ} \mathrm{S}$, positive SSTAs are not consistent with enhanced latent hear fluxes in COADS, suggesting importance of ocean dynamics such as meridional Ekman heat transport [Colberg et al., 2004].

[10] To evaluate the contributions from wind speed anomaly and from anomalous air-sea difference in specific humidity (corresponding to saturation specific humidity anomaly at the sea surface $q_{o}^{* \prime}$ minus air specific humidity anomaly $q_{a}^{\prime}$ ), we approximately represent the latent heat flux anomaly by three linearized components as in the work by Enfield and Mayer [1997] and Tanimoto et al. [2003]:

$$
F_{l h}^{\prime} \approx \rho c_{e} L_{e}\left\{W^{\prime}\left(\overline{q_{o}^{*}}-\overline{q_{a}}\right)+\bar{W}\left(q_{o}^{* \prime}-q_{a}^{\prime}\right)\right\}
$$

where $F_{l h}$ is the latent heat flux (upward positive), and the overbar and prime indicate the monthly climatological mean and anomaly, respectively (for more details see Chikamoto and Tanimoto [2005]). On the right-hand side of (1), the first and the second terms represent contributions from wind speed anomaly $\left(W^{\prime}\right)$ and from anomalous air-sea difference in specific humidity $\left(\Delta q^{\prime}\right)$ to the total amount of latent heat flux anomalies, respectively.

[11] Figure 2 shows composite difference maps of $W^{\prime}$ and $\Delta q^{\prime}$ components to total latent heat flux anomalies. Over the northern tropical Atlantic, reduced latent heat fluxes caused by $W^{\prime}$ component extending from the Caribbean Sea to the west coast of Africa are observed (Figures 2a and 2c), consistent with anomalous surface southwesterlies in Figures $1 \mathrm{a}$ and $1 \mathrm{c}$. Over this region, $\Delta q^{\prime}$ components are not so apparent in both datasets (Figures $2 b$ and $2 d$ ). As a result, reduced latent heat flux mainly induced by the $W^{\prime}$ component contributes in forming positive SSTAs in the northern tropical Atlantic as suggested by previous studies [Curtis and Hastenrath, 1995; Enfield and Mayer, 1997; Klein et al., 1999; Giannini et al., 2000; Lau and Nath, 
(a) COADS

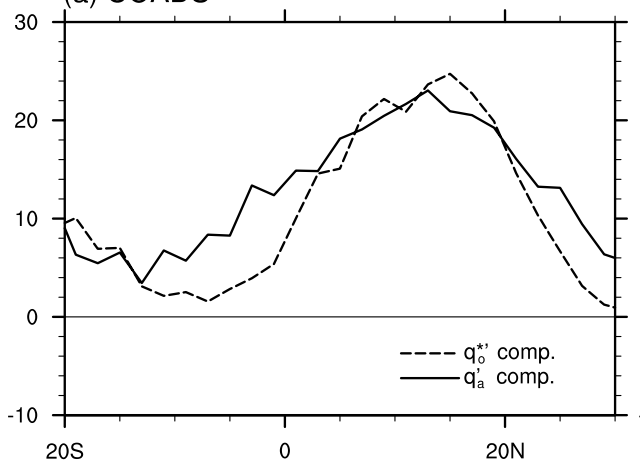

(b) NCEP2 \& OISST

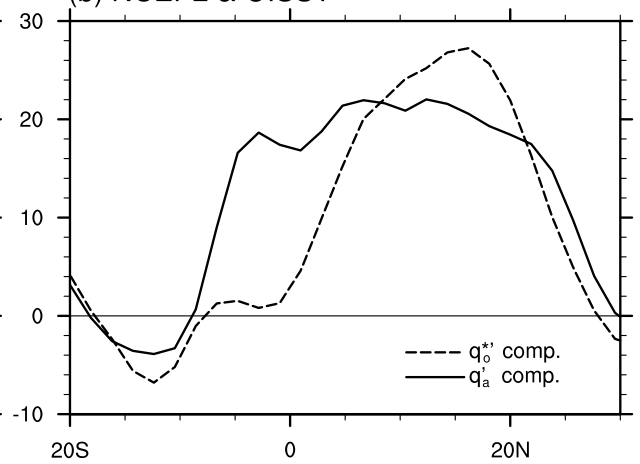

Figure 3. Latitude distributions of contributions from saturation specific humidity at the sea surface ( $q_{o}^{* \prime}$, dashed lines) and from air specific humidity anomaly ( $q_{a}^{\prime}$, solid lines) to latent heat flux anomalies based on (a) COADS and (b) NCEP2 and OISST. These anomaly components are zonally averaged over the tropical Atlantic $\left(70^{\circ} \mathrm{W}-0^{\circ}\right)$. Units are $\mathrm{W} \mathrm{m}^{-2}$. Deference between the $q_{o}^{* \prime}$ and $q_{a}^{\prime}$ components is identical to the $\Delta q^{\prime}$ component.

2001]. Over the southern tropical Atlantic, by contrast, reduced latent heat fluxes caused by the $\Delta q^{\prime}$ component are observed in NCEP2 and OISST (Figure 2d), countering the increased latent heat fluxes caused by the $W^{\prime}$ component (Figures $2 \mathrm{a}$ and $2 \mathrm{c}$ ). In COADS, the $\Delta q^{\prime}$ component also tends to show reduced latent heat fluxes over the southern tropical Atlantic with latitude band $0-10^{\circ} \mathrm{S}$ although there are some missing values in this region (Figure $2 b$ ). Monthly plots of $\Delta q^{\prime}$ represents the similar structures with the same polarity in MAM period (not shown).

[12] Once positive SSTAs are formed in the northern tropical Atlantic during late winter associated with the ENSO warm events, negative anomalies of sea level pressure (SLP) are also observed over that region. These negative SLP anomalies produce an anomalous southerly flow across the equator through anomalous meridional SLP gradient. In the off-equatorial region, these anomalous southerlies are altered by Coriolis force, thereby inducing anomalous southwesterlies over northern tropical Atlantic and southeasterlies over southern one, respectively [Xie and Philander, 1994; Chang et al., 1997; Xie and Tanimoto, 1998; Okumura et al., 2001; Chiang et al., 2002]. Over the tropical Atlantic, these wind anomalies in FMA period tend to show the equatorial antisymmetric structure of $W^{\prime}$ component between north and south of the equator, as we have seen in Figures $2 \mathrm{a}$ and $2 \mathrm{c}$. Thus, the $W^{\prime}$ component acts to produce the equatorial antisymmetric structure in the latent heat flux anomaly field, while the $\Delta q^{\prime}$ component acts to reduce this equatorial antisymmetric structure.

[13] The $\Delta q^{\prime}$ component is divided into $q_{o}^{*^{\prime}}$ and $q_{a}^{\prime}$ components as in equation (1). Figure 3 shows a meridional plot of the $q_{o}^{* \prime}$ and the $q_{a}^{\prime}$ components averaged over the tropical Atlantic from $70^{\circ} \mathrm{W}$ to $0^{\circ}$. The $q_{o}^{* \prime}$ components in both datasets show positive anomalies north of the equator, while those components are quite small south of the equator (dashed line in Figure 3) because positive SSTAs are observed only north of the equator. The $q_{a}^{\prime}$ components, on the other hand, show positive anomalies in both hemispheres extending from $10^{\circ} \mathrm{S}$ to $30^{\circ} \mathrm{N}$ (solid line in Figure 3), where the signal is statistically significant at the $95 \%$ level. Over the southern tropical Atlantic, therefore, $q_{o}^{*^{\prime}}-q_{a}^{\prime}$ results in significant negative anomalies of the $\Delta q^{\prime}$ components. Chikamoto and Tanimoto [2005] indicated the important contribution of $q_{a}^{\prime}$ in forming SSTAs in the northern tropical Atlantic during the mature stage of the ENSO events (the January-February period). Following this stage (the MAM period), the significant $q_{a}^{\prime}$ component still persists in the northern tropical Atlantic as we have seen in Figure 3, while $q_{o}^{*^{\prime}}-q_{a}^{\prime}$ becomes quite small due to the SSTA formation over that region. As a result, significant $\Delta q^{\prime}$ component is observed only south of the equator in the FMA period.

\section{Discussion}

[14] To examine the formation of positive $q_{a}^{\prime}$ over the southern tropical Atlantic, we made vertical profiles of anomalous air humidity and temperature based on NCEP2 averaged over the southern tropical Atlantic $\left(40^{\circ} \mathrm{W}-0^{\circ}, 0-\right.$ $10^{\circ} \mathrm{S}$; solid line) and at Ascension Island $\left(8^{\circ} \mathrm{S}, 14^{\circ} \mathrm{W}\right.$; dashed line) based on CARDS as shown in Figure 4. In both profiles, significant positive anomalies in specific humidity (above the 90\% level) are observed in the lower atmosphere (Figure 4a), contributing to the reduced latent heat fluxes caused by $\Delta q^{\prime}$ component over the southern tropical Atlantic (Figures $2 \mathrm{~b}$ and 2d). In the middle and upper troposphere, positive air temperature anomalies are observed above $900 \mathrm{hPa}$ in both datasets (Figure 4b). This temperature warming stabilizes the atmosphere above the planetary boundary layer, increasing the moisture storage capacity in the lower atmosphere. In fact, the atmospheric layer between 900 and $800 \mathrm{hPa}$ is stabilized during the ENSO warm events (Figure 4c). In the lower atmosphere, the increase in the moisture storage capacity is associated with an increase in air specific humidity, so as to conserve CAPE. This increase in air specific humidity produces the $q_{a}^{\prime}$ component south of the equator, countering the $W^{\prime}$ component. Previous studies indicated that tropospheric temperature warming is observed in the whole tropics after the ENSO warm events [Wallace et al., 1998]. According to Chiang and Sobel [2002] and Chiang and Lintner [2005], this tropospheric temperature warming accompanies an increase in equivalent potential temperature in the planetary boundary layer under the SQE concept [Brown and Bretherton, 1997; Emanuel et al., 1994]. Our vertical profiles actually show the large positive specific humidity 

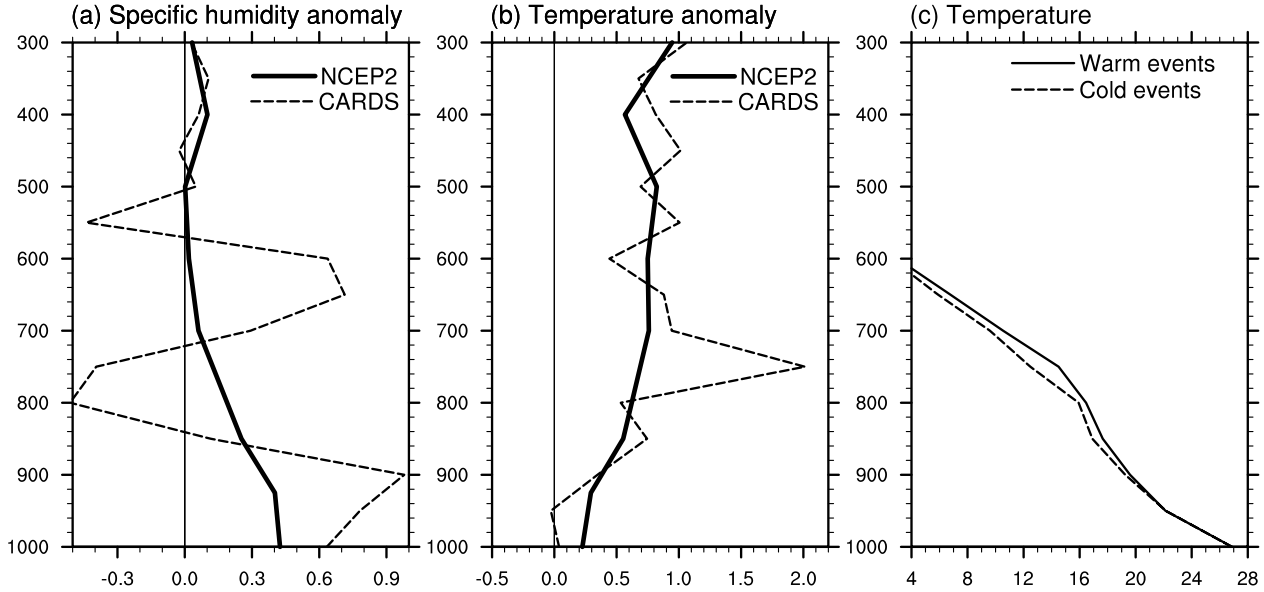

Figure 4. Vertical profiles of (a) specific humidity anomaly and (b) temperature anomaly based on NCEP2 averaged over the southern tropical Atlantic $\left(40^{\circ} \mathrm{W}-0^{\circ}, 0-10^{\circ} \mathrm{S}\right.$, solid lines) and CARDS $\left(8^{\circ} \mathrm{S}, 14^{\circ} \mathrm{W}\right.$, dashed lines $)$ in the FMA period. (c) Vertical temperature profiles during the ENSO warm and cold events based on CARDS are plotted by solid and dashed lines, respectively.

anomalies in the planetary boundary layer, while temperature anomalies in the same layer are essentially zero (Figures $4 \mathrm{a}$ and $4 \mathrm{~b}$ ). These results are consistent with the suggestion proposed by Chiang and Sobel [2002] and Chiang and Lintner [2005]: the increase in $q_{a}^{\prime}$, rather than changes in wind speed, associated with the tropospheric temperature warming during the ENSO warm events affects the underlying SSTAs over the tropical Atlantic through reduced latent heat fluxes, resulted in new warmer SST state equilibrating to the tropospheric temperature warming above.

\section{Summary}

[15] We examined why no significant SSTAs are observed in the southern tropical Atlantic over $0-10^{\circ} \mathrm{S}$ band after the mature stage of the ENSO events. Based on the linearized component of latent heat flux anomalies, we showed that the $W^{\prime}$ component has the equatorial antisymmetric structure over the tropical Atlantic (Figure 2), while the $q_{a}^{\prime}$ component is the equatorial symmetric structure associated with tropospheric temperature warming (Figure 3). These anomalous wind speed and humidity effects tend to reinforce each other in the northern tropical Atlantic but opposes each other in the southern tropical Atlantic. As a result, latent heat flux anomaly and hence SSTA showed the large amplitude north of the equator and small one south of the equator after the mature stage of the ENSO events.

[16] Our analysis suggests two surface processes involved in anomalous latent heat fluxes in the tropical Atlantic associated with the ENSO events. One is the $W^{\prime}$ component, which is associated with trade wind changes in the tropical Atlantic affected by the ENSO forcing [Chiang et al., 2002; Czaja et al., 2002] and further maintained by air-sea interaction confined in the tropical Atlantic [Xie and Philander, 1994; Chang et al., 1997; Xie and Tanimoto, 1998; Okumura et al., 2001]. The other is the $q_{a}^{\prime}$ component, which is probably induced by the atmospheric thermodynamic remote response to the ENSO events. The combination of these internal and external forcing may explain the reason why the tropical Atlantic SST variability tends to show larger fluctuations in the northern hemisphere than in the southern one [Houghton and Tourre, 1992; Enfield and Mayer, 1997; Xie and Tanimoto, 1998; Tanimoto and Xie, 2002]. Recent numerical experiments indicate that radiative heat fluxes act against latent heat fluxes in the tropical Atlantic [e.g., Chiang and Lintner, 2005]. Accurate surface observations of surface heat flux components are highly desired.

[17] Acknowledgments. The authors are grateful to K. Yamazaki, Y. Fujiyoshi, M. Watanabe, H. Ueda, S.-P. Xie, and H. Mukougawa for their stimulating discussions. The manuscript benefited from the constructive comments by C. Reason, J. Chiang, and anonymous reviewers. This work was partly supported by a grant-in-aid for Scientific Research defrayed by the Ministry of Education, Culture, Sports, Science and Technology of Japan (17340137), KAGI21, and the Sumitomo Foundation.

\section{References}

Alexander, M., and J. Scott (2002), The influence of ENSO on air-sea interaction in the Atlantic, Geophys. Res. Lett., 29(14), 1701, doi:10.1029/2001GL014347.

Brown, R. G., and C. S. Bretherton (1997), A test of the strict quasiequilibrium theory on long time and space scales, J. Atmos. Sci., 54, 624-638

Chang, P., L. Ji, and H. Li (1997), A decadal climate variation in the tropical Atlantic ocean from thermodynamic air-sea interactions, Nature, $385,516-518$.

Chiang, J. C. H., and B. R. Lintner (2005), Mechanisms of remote tropical surface warming during El Niño, J. Clim., 18, 4130-4149.

Chiang, J. C. H., and A. H. Sobel (2002), Tropical tropospheric temperature variations caused by ENSO and their influence on the remote tropical climate, J. Clim., 15, 2616-2631.

Chiang, J. C. H., Y. Kushnir, and A. Giannini (2002), Deconstructing Atlantic Intertropical Convergence Zone variability: Influence of the local cross-equatorial sea surface temperature gradient and remote forcing from the eastern equatorial Pacific, J. Geophys. Res., 107(D1), 4004, doi:10.1029/2000JD000307.

Chikamoto, Y., and Y. Tanimoto (2005), Role of specific humidity anomalies in Caribbean SST response to ENSO, J. Meteorol. Soc. Jpn., 83, 959-975.

Colberg, F., C. J. C. Reason, and K. Rodgers (2004), South Atlantic response to El Niño-Southern Oscillation induced climate variability in an ocean general circulation model, J. Geophys. Res., 109, C12015, doi:10.1029/2004JC002301.

Covey, D. L., and S. Hastenrath (1978), The Pacific El Niño phenomenon and the Atlantic circulation, Mon. Weather Rev., 106, 1280-1287. 
Curtis, S., and S. Hastenrath (1995), Forcing of anomalous sea surface temperature evolution in the tropical Atlantic during Pacific warm events, J. Geophys. Res., 100, 15,835-15,847.

Czaja, A., P. van der Vaart, and J. Marshall (2002), A diagnostic study of the role of remote forcing in tropical Atlantic variability, J. Clim., 15, $3280-3290$.

Emanuel, K. A., J. D. Neelin, and C. S. Bretherton (1994), On large-scale circulations in convecting atmospheres, Q. J. R. Meteorol. Soc., 120, $1111-1143$

Enfield, D. B., and D. A. Mayer (1997), Tropical Atlantic sea surface temperature variability and its relation to El Niño-Southern Oscillation, J. Geophys. Res., 102, 929-945.

Eskridge, R. E., et al. (1995), A Comprehensive Aerological Reference Data Set (CARDS): Rough and systematic errors, Bull. Am. Meteorol. Soc., 76, 1759-1775.

Giannini, A., Y. Kushnir, and M. A. Cane (2000), Interannual variability of Caribbean rainfall, ENSO, and the Atlantic Ocean, J. Clim., 13, 297311.

Hastenrath, S. (2000), Upper air mechanisms of the Southern Oscillation in the tropical Atlantic sector, J. Geophys. Res., 105, 14,997-15,009.

Houghton, R. W., and Y. M. Tourre (1992), Characteristics of lowfrequency sea surface temperature fluctuations in the tropical Atlantic, J. Clim., 5, 765-771.

Huang, B., P. S. Schopf, and Z. Pan (2002), The ENSO effect on the tropical Atlantic variability: A regionally coupled model study, Geophys. Res. Lett., 29(21), 2039, doi:10.1029/2002GL014872.

Kanamitsu, M., et al. (2002), NCEP-DOE AMIP-II reanalysis (r-2), Bull. Am. Meteorol. Soc., 83, 1631-1643.

Klein, S. A., B. J. Soden, and N. C. Lau (1999), Remote sea surface temperature variations during ENSO: Evidence for a tropical atmospheric bridge, J. Clim., 12, 917-932.

Lau, N. C., and M. J. Nath (2001), Impact of ENSO on SST variability in the North Pacific and North Atlantic: Seasonal dependence and role of extratropical air-sea coupling, J. Clim., 14, 2846-2866.

Liu, Z., Q. Zhang, and L. Wu (2004), Remote impact on tropical Atlantic climate variability: Statistical assessment and dynamic assessment, J. Clim., 17, 1529-1549.
Okumura, Y., S. P. Xie, A. Numaguti, and Y. Tanimoto (2001), Tropical Atlantic air-sea interaction and its influence on the NAO, Geophys. Res. Lett., 28, 1507-1510.

Reason, C. J. C., R. J. Allan, J. A. Lindesay, and T. J. Ansell (2000), ENSO and climatic signals across the Indian ocean basin in the global context: Part I. Interannual composite patterns, Int. J. Climatol., 20, 1285-1327.

Reynolds, R. W., et al. (2002), An improved in situ and satellite SST analysis for climate, J. Clim., 15, 1609-1625.

Saravanan, R., and P. Chang (2000), Interaction between tropical Atlantic variability and El Niño-Southern Oscillation, J. Clim., 13, 2177-2194.

Tanimoto, Y., and S. P. Xie (2002), Inter-hemispheric decadal variations in SST, surface wind, heat flux and cloud cover over the Atlantic Ocean, J. Meteorol. Soc. Jpn., 80, 1199-1219.

Tanimoto, Y., H. Nakamura, T. Kagimoto, and S. Yamane (2003), An active role of extratropical sea surface temperature anomalies in determining anomalous turbulent heat flux, J. Geophys. Res., 108(C10), 3304, doi:10.1029/2002JC001750.

Wallace, J. M., E. M. Rasmusson, T. P. Mitchell, V. E. Kousky, E. S. Sarachik, and H. von Storch (1998), On the structure and evolution of ENSO-related climate variability in the tropical Pacific: Lessons from TOGA, J. Geophys. Res., 103(C7), 14,241-14,260.

Woodruff, S. D., R. J. Slutz, R. L. Jenne, and P. M. Steurer (1987), A comprehensive ocean-atmosphere data set, Bull. Am. Meteorol. Soc., $68,1239-1250$.

Xie, S. P., and S. G. H. Philander (1994), A coupled ocean-atmosphere model of relevance to the ITCZ in the Eastern Pacific, Tellus, Ser. A, 46, $340-350$.

Xie, S. P., and Y. Tanimoto (1998), A Pan-Atlantic decadal climate oscillation, Geophys. Res. Lett., 25, 2185-2188.

Y. Chikamoto, Disaster Prevention Research Institute, Kyoto University, Gokasyo, Uji-shi, Kyoto 611-0011, Japan. (chika44@dpac.dpri.kyotou.ac.jp)

Y. Tanimoto, Faculty of Environmental Earth Science, Hokkaido University, N10W5, Kita-ku, Sapporo, 060-0810, Japan. 